\title{
Effective Service Delivery: A Leadership Challenge For Policing
}

\author{
Johan van der Merwe \\ Johan van Graan
}

Department of Police Practice, School of Criminal Justice, Faculty of Law,

University of South Africa, South Africa

Wilfred I. Ukpere

Department of Industrial Psychology and People Management, Faculty of Management University of Johannesburg, South Africa

\author{
Doi:10.5901/mjss.2013.v4n14p627
}

\begin{abstract}
In this contemporary era of personnel management little emphasis needs to be placed on organisational performance, but rather what actions requires better performance. This paper reflects why efficient service delivery provided by the South African Police Service (SAPS) is lacking despite a legislative and policy framework promoting improved service delivery. It further deliberates on the role of the SAPS leadership to optimize service delivery and dwells on SAPS leadership competencies in order to move beyond mere policy on paper to render sound service to the public. An overview of performance management and leadership in public sector organizations indicates that visionary ability and skills of leadership to convert policy into practice are fundamental for service delivery to succeed. As a result, a direct link between leadership and performance management can be supported.
\end{abstract}

Keywords: Service delivery; Leadership; Performance management; Public sector organizations; South African Police Service

\section{Introduction}

The South African Police Service (SAPS) leadership is facing challenges to improve service delivery in the organization. Various legislative and policy directives exist. However, the implementation thereof poses huge challenges resulting in insufficient service delivery provided by the SAPS, which is regularly appearing in the media (Faull, 2010). Public perception emphasising a lack of efficient service delivery to communities is on the increase and is evidenced by the upsurge of the number of public protests concerning SAPS service delivery (Bouckaert, 1992). In addition, taxpayers, who are the financiers of government, increasingly probe the cost effectiveness of their tax money and how efficient policing services are being delivered. On the one hand, reasons for this mediocre service delivery range from apathetic attitudes of police members to the lack of training and skills (Burger, 2013). On the other hand, the role of leadership in providing efficient services to the community has received little attention. Leadership in the public service is not only about the occupation of high office or rank but should include, inter alia, visionary ability, leadership skills, motivation of staff and the continuous strive to improve service delivery. Moreover, efforts directed at converting the SAPS to a postbureaucratic organisation and introducing managerialism has not thoroughly taken root.

\subsection{Problem statement}

Despite a legislative and policy framework directed at improving service delivery in the SAPS efficient service delivery continues to afflict the organization. The mere existence of various policy directives is insufficient if not efficiently driven and supported by leaders, effective systems and processes for concrete implementation. Causative factors to the substandard services delivered by the SAPS could, to a great extent, be related to weak organisational leadership and the failure to effectively implement directives. 


\subsection{Research questions}

The following research questions will be addressed in this paper:

- What is the role of the SAPS leadership in optimising police service delivery?

- How can the leadership of the SAPS execute the implementation of the policy framework advocating improved service delivery?

\subsection{Research objectives}

The research objectives of this paper are:

- To sensitize the reader of the responsibilities of police leadership to improve service delivery.

- To recommend possible leadership approaches to successfully implement policy directives aiming to improve police service delivery.

\subsection{Research methodology}

The paper is a qualitative explorative study that is based on conceptual analysis and theory building. It reflects on the role of the SAPS leadership in optimising police service delivery and looks into the implementation of the policy framework advocating improved service delivery from the authors' perspective.

\section{Leadership and Management in the Public Service}

\subsection{Leadership}

The manner in which the leader exercises power and influence, in order to carry out leadership functions is often referred to as leadership style (Cordner, 2010:290-291). Leadership styles may differ from situation to situation. Although the subject of leadership has been extensively studied, the leadership phenomenon, in general, still escapes scientific understanding and remains an elusive concept. Stodgill (1974), for example, claimed to have reviewed seventy two different definitions of leadership without coming to some agreement on an appropriate acceptable definition, while Bennis and Nanus (1985:4) considered that the definitions leadership is in excess of three hundred and fifty. Until now the concept of leadership continues to be something everyone knows exist but sometimes difficult to define. Most of the definitions of leadership are not only acceptable today but also relevant. In this synthesis of leadership literature and discussion of the concept of leadership, Parry's (1996) defines leadership as "the presentation by a leader of some identifiable goal, vision or future state that people can desire and the generation of a willingness within those people to follow the leader along a socially responsible and mutually beneficial course of action towards a goal", seems satisfying and acceptable for the purpose of this article. Responsible leadership is important in the SAPS as a result of the power leaders are bestowed or "the basic energy to initiate and sustain action and translating intention into reality" (Bennis and Nanus 1985:15).

According to Cordner (2010:300-301) police leaders operate in an environment that includes the constraining influences of politics, law, other interdependent agencies, police fraternal organizations and unions, budgets and human behaviour. There are a number of functions that leaders perform, a number of ways they go about performing them and a number of theories about which ways are the best. Police leaders have the responsibility to exert leadership in seeking to improve the quality of police service and in seeking to solve community problems of concern to the police.

\subsection{Management and administrative efficiency}

In the public sector, leaders and managers are more clearly defined with management being organisationally based while leadership is confined to the political level (Bouchaert, 1992). There may be grey areas, but this division is more pronounced in this sector. However, Lungu (1998) disagree and view the line separating politics from public management as too fine to be visible and further postulates that the authority, which originates from the power of mandate, that career officials exercise in their own right also offer career officials a wide political latitude. Despite these differences in views, roles between the two, public manager and politician continue to be defined by the weaknesses existing in each function, which allow the other to occupy the result vacuum. It may be for this reason that the direction of management 
development programmes tends to be biased more towards making public managers leaders as well. The advantage in this approach is that when managers become leaders their skill of playing the influence game is actually sharpened. Cascio (1991:318) calls this influence game the Leadership Motive Pattern. Being skilled in both leadership and management in a balanced manner obviously should benefit public service delivery. However, public managers will have to guard against the danger of over-management and under-leading or vice versa. Lack of maintaining this balance may result in, for instance, a manager excelling in daily routine police work and sometimes questioning whether the function needs to be done at all.

\section{The South African Police Services' Readiness to Deliver Effecient Services}

Service delivery and organisational readiness refers to the ability of the public institutions to convert policies into actions and viable field operation (Starling, 1998: 413), which is something that is not easy, because of the conversion requirements. The conversion process entails bargaining and the realisation that some functions are based on the success of others and the management of intergovernmental relations. Normally organisational readiness is assumed when policy reaches the implementation stage (Pressman \& Wildavsky, 1973). Organisational readiness involves the availability and readiness for use of all resources including systems, people's attitudes, ability and finances. In general terms, policy implementation involves a single government department, but when such policy is in the form of a programme it requires multiple organizations for implementation to succeed and it is at this stage that problems of coordination come into play. Without access to and control of the other department's processes, better performing departments within the programme may be demotivated. Territorial politics, different priorities and even organisational jealousy may impair progress. The criminal justice system, including the SAPS, needs to function as one programme to focus on the criminal elements in society.

\subsection{Governance as implementation tool}

Co-operative government and governance provide a platform for mobilising resources from multiple stakeholders driven by the need to deliver quality services. The South African public services' version of co-government is the cluster system through which different departments co-operate for the purposes of delivering a common service. Witnessed in situations of co-operative actions are new models of governing (Bouckaert and Halachmi, 1995: 1) among which is the Emmandish Collective Management Model where co-leadership is a core attribute of collective management (Tshikwatamba, 2003: 308). These models make frequent use of the prefix "co-" which includes co-management, co-production, co-allocation, all attempting to manoeuvre through the increasing complexity, dynamism and diversity (Kooiman, 1993) which are part of current governing systems. Readiness under these circumstances is organisational flexibility and readiness to accept that not only are internal structures responsible but, also the need to accept external stakeholder and the provision of space for them to function in their own terrain.

\subsection{Proactive implementation assessment and visioning}

Pre-implementation planning and visioning should provide a starting point in the organizational readiness process and the implementation of government programmes. However, in most instances, the formulation-implementation gap that a strategic plan is supposed to bridge, remains despite compliance based on planning processes. Pre-implementation assessment of organisational capacity and integration of all organisational processes and resources towards the accomplishment of goals are to be undertaken for service delivery to succeed. This organisational capacity assessment includes the capacity and assessment of the ability to learn and overcome structural inertia (Sepic, 1996) ability to provide performance feedback and measure performance through ends and not means (Behn, 1995:314).

\subsection{Innovation, culture and service delivery in policing}

Police service managers, more specific the senior police officers, need to be motivated towards being innovative and able to take risks if service delivery is to move beyond experimentation. Understandably, innovation and risk taking are expensive to implement and more so when initiatives fail because consequences for failure are sometimes serious and may include punishment. Balk (1995: 327) refers to the existence of limits to energetic leadership, empowerment and employee training making innovation the next available remedy for organisational improvement. Organisational 
innovations can be untidy as they mostly involve changes in policies and behaviour of employees including adjustment to new circumstances.

Impeding innovation in the SAPS is due to inter alia the lack of space to express ideas because of the existence of traditional hierarchical norms of loyalty and trust which engender fear and silence. Cordner (2010:236) states that organizational traditions are customary ways of doing things and cannot be changed easily or frivolously. This is why many insiders say that efforts to change the police, whether the change concerns traditional ideas of patrol, getting officers to talk about corrupt fellow officers, even changing the type of weapons they carry, must first win the hearts and minds of its officers. Until advocates of police change recognize the importance of culture, they will continue to be surprised as they have been for the past years. Bureaucracy and hierarchy perpetuate isolation and specialisation both of which are elements that do not promote innovation. For a public organisation, like the SAPS, to be innovative a serious cultural re-orientation will have to be undertaken.

\subsection{Attitude of police members}

Maier in Cordner (2010:217) describes an attitude as a psychological mental set that represent a predisposition to form certain opinions. Attitudes may be ideals, values, sentiments, thoughts, ideas, concepts, feelings, beliefs and assumptions. Attitudes affect people's perceptions, behaviour and events. People with different attitudes will form different opinions of the people with whom they associate. They will also evaluate events and activities in which they are involved differently, depending on their attitudes. They will perceive their fellow staff, their commanding officers, the citizens of their communities, their own environment, their salaries, the way they are treated and everything they do according to their opinions or attitudes (Cascio, 1991). Thus, attitudes are what people are predisposed to bring to everything in which they become involved. Cordner (2010:217) mentions further that the relationship between attitudes and behaviour, however, is not a direct one. For example, some people have the attitude that their work is mindnumbing, yet they remain working. Some police officers believe that their sergeants are incapable of supervising, yet they follow orders. Others believe that their police chiefs deserve their best efforts each and every day, but nonetheless find themselves coasting in their jobs. Although how people behave is affected by their attitudes, behaviour is also influenced by many other factors.

The change of attitude begins within every individual. Police members should focus on an attitude change towards their communities and channel their focus to work smarter, not harder. This shift in attitude could result in drastic positive changes in the quality and enhancement of policing service delivery. Police organizations needs well trained and committed members with a passion to serve their communities. Members need to demonstrate determination, tenacity, dedication and a willingness to really protect and to serve. According to Cordner (2010:221-222) a major challenge for police managers is to harness these powerful peer influences so that young officers attitude change positively rather than negatively. Although distrust and cynicism are among the common effects of police work and the police culture on young officers, it is also possible for officers to remain optimists or become realists but avoid developing into pessimists or cynics.

In 2006 the SAPS introduced the Executive Development Learning Programme (EDLP) to equip senior managers with knowledge, skills and pertinent attitudes for enhanced service delivery in the organization. The programme puts emphasis on generic management principles and the fostering of effective internal administration processes (Sepaela, 2013:18).

\section{Role of Performance Measurement in Improving Service Delivery}

\subsection{Performance measurement framework for policing}

The need for performance improvement and measurement in the public service was realised from the beginning of the democratic era in South Africa, and mechanisms to deal with it was put into place. Firstly, a performance vision was codified through the enactment of the Constitution of the Republic of South Africa 108 of 1996, (South Africa, 1996: sec 195), and the various supportive policies and legislation (Msengana-Ndlela, 2004). Secondly, a number of policies, such as, the White Paper on Reconstruction and Development (RDP) (South Africa, 1994: sec 5.7) which visualised an introduction of a performance measurement system, the White Paper on Transforming Public Service Delivery (South Africa, 1997: sec 1.1.2), which requires that service standards to which government departments will be held accountable be set. These were followed by the Public Service Regulations, 1999 (South Africa, 1999) which require the creation of a 
link between individuals and agreed to performance outputs while the Public Finance Management (PFMA), 1999 (South Africa, 1999) deal with the organisational part of performance from a finance perspective. The citizens of South Africa need to know how well the police department is performing. It is the right and obligation of citizens to probe the police to ascertain whether and to what degree the community's public safety needs are being met. According to the National Commissioner of the SAPS, General Phiyega the SAPS strategic direction was hugely influenced by the recently adopted National Development Plan (NDP), where all people living in South Africa would feel safe and also appealed to senior management to provide good leadership (Sepaela, 2013:12). According to Burger (2013:1) the NDP contains a number of far-reaching recommendations, which, if implemented, could see dramatic improvements not only in policing but throughout government. It was developed by the National Planning Commission (NPC) in the office of the Presidency and was endorsed by the South African Cabinet at a lekgotla in September 2012. The NDP recognises that reducing crime and violence requires far more than the police alone can achieve. The plan recognises the deterioration in police professionalism following years of poor appointments of both senior and middle managers as well as the crises of top management. If the political will exists to implement the NDP recommendations, the plan can go a long way towards developing a professional police service for South Africa.

\subsection{Performance measurement as an instrument for policing management accountability}

Management is being accountable and able to achieve the required or expected performance. While measurement is much clearer in private organisations, public accountability forces public organisations to be more accountable if not more than their private counterparts because of a lack of the in-built profit incentive. According to Bouckaert (1995: 383) the role of management is concerned with how performance standards are set and whether the way they are set, leads to commitment within the management process. The importance of having a performance management system lies in its ability to ensure that there is organisational alignment of effort from the vision and mission, including policy and strategy to organisational and individual performance. Crime statistics can only offer limited measurement of police performance, if they can be a measure of performance at all. According to Faull (2010:19) to put pressure on the police to reduce crime statistics leads to perverse incentives, typically to not record crime. But still in South Africa, crime statistics are still seen as a measure of police performance rather than a measure of the challenge facing the police, and indeed society as a whole. Other police performance assessment measures currently in place also contribute to poor and abusive policing practices. Police in democratic societies operate in a space forged between their constitutional mandate and the legal framework that defines how they must operate. Such a mandate is impossible for a police service alone to achieve, yet statements by police leaders, research on police culture suggest most police members nonetheless embrace the mandate (Faull, 2010:19). The South African Police Service (SAPS) currently uses a performance chart which actually ignores the importance of community perceptions of police performance. Ultimately the police need to satisfy the public. Faull (2010:24) further states that acclaimed police academic, David H. Bayley, suggests that for a police service to be truly effective it must demonstrate that it is responsive, available and fair to the population. He bases this on the premise that police are the tool for legitimising the law and mobilising public support for a moral regime. Bayley believes only about fifteen police organisations in the world realise this mandate of responsiveness, availability and fairness. The SAPS is not one of them. In this light, police leadership in South Africa could be said to be sending the wrong message.

Performance management and measurement as a management function, means setting goals, defining strategies and programmes and achieving those goals and establishing systems to evaluate progress. This conceptual simplicity is one of the greatest strengths of performance measurement and management systems.

\subsection{Leadership, performance measurement and incentives for policing}

Performance measurement is likely to have consequences on the salary and incentive payment structures resulting from the achievement of positive results, senior employees become eligible for bonuses. In the light of enronism, the public is unlikely to accept the efficiency bonuses paid to public sector executives and managers as has been the recent case with the South African electricity utility ESKOM after the discovery that the performance of this company has not been efficient. The credibility and legitimacy of the public servants can be doubted. Incentives result from a prior agreement on what the agreed to exchange will entail. This exchange or transaction, which requires management, involves an incentive for the delivery of an agreed to level of performance.

The transactional leadership approach is based on the exchange theory according to which negotiation, a minimum positive level, where reward becomes greater than the cost of an outcome must exist in order for attraction or 
affiliation to take place (Luthans, 1981: 320). While the kind of deliberations taking place within a group that has different views on an issue seems simple, it is in actual sense a complex exchange and bargaining. Citizens, political officials and police officials need information with which to judge overall police department performance. Traditional methods that rely completely on crime and arrest statistics are inadequate. A more comprehensive approach should include accepted standards of police practice, sensitive quantitative measures that assess quality as well as quantity and subjective judgements about the style, philosophy and quality of police services, police policies and the total police administration.

Performance management and productivity is an area that has been found to lead to more conflict when compared to other areas related to employment. Conflict normally involves two or more people over values, competition for status, power and scarce resources. Conflict results from communication, which according to Fox, Schwella and Wissink (1991:177) may either be too much, too little or does not exist at all. Not all conflict is disruptive and certain levels of conflict should be maintained in an organisation for it to maintain its innovativeness. The SAPS, due to its size and possible resultant organisational complexities could be a breeding ground for internal conflict and could also lead to low morale. It, therefore, becomes imperative for the leaders, the senior officers and top ranks, in the police department to understand how to deal with conflict situations and resultant low morale.

\section{Conclusion}

The ultimate determinant of police service performance is general public opinion. Irrespective of how good the department looks on statistics, it fails in democratic terms if the community are not satisfied. The perception from the broad community of the SAPS' inability to provide efficient services to citizens should be addressed by management. Public perception cannot be easily reversed by means of the normal organisational change methods or good public relations exercises but require radical change intervention. Part of the leadership challenge in the police department is to ensure strategies to control this perception.

The continuing high levels of violent crime in South Africa such as murder, robbery, rape and other forms of aggravated murder and robbery has become a source of international discomfiture. The SAPS needs leaders that can devise strategy, identify weaknesses and rectify where policy fails and demonstrate great courage, foresight, decisive leadership and clarity of vision for improving services to South Africans.

\section{References}

Balk, W.L. (1995). Managing Innovation and Reform. In Halachmi and Bouckaert (Eds.) The Enduring Challenges in Public Management: Surviving and Excelling in a Changing World. San Francisco: Jossey-Bass Publishers.

Behn, R.D. (1995). The Big Question of Performance Management. Public Administration Review, 55(4):313-324.

Bennis, W.G. and Nanus. (1985). Leaders: The Strategy for Taking Change. Cambridge, Mass: Harper and Row.

Bouckaert, G. (1992). Public Productivity in Retrospective. In Holzer, M. (ed.) Public Productivity Handbook. New York: Marcel Dekker Inc.

Bouckaert G \& Halachmi A. (1995). Introduction: The Challenges of Management in a Changing World. In Halachmi and Bouchaert (Eds.) The Enduring Challenges in Public Management: Surviving and Excelling in a Changing World. San Francisco: JosseyBass Publishers.

Burger, J. (2013). The National Development Plan can improve policing in South Africa. From: http://www.issafrica.org /iss today.php?ID=1626 (accessed 19 April 2013).

Cascio, W. $\bar{F}$. (1991). Applied Psychology in Personnel Management. New Jersy: Prentice Hall International Inc.

Cordner,W.G and Scarborough,K.E. (2010). Police Administration.United States: Matthew Bender \& Company, Inc.

Faull, A. (2010). When measuring performance undermines police effectiveness. South African Crime Quarterly, 31: 19-25.

Fox, Schwella, E. and Wissink, H.J. (1991). Public Management. Cape Town: Juta \& Co. Ltd.

Kooiman, J. (1993). Governance and Governability: Using Complexity, Dynamism and Diversity. In Kooiman (Eds.) Modern Governance. London: Sage.

Kuper, A \& Kuper, J (Eds.) (1985). The Social Science Encyclopaedia. London: Routledge and Kegan Paul.

Lungu, G.F. (1998). Civil Service Neutrality in Aglophone Africa: A Model for new Multiparty Democracies. African Journal of Public Administration and Management, December: 2.

Luthans, F. (1981). Organisational Behaviour. Third Edition. London: McCraw-Hill International Book Company.

Osborne, D. and Gaebler, T. (1993). Reinventing Government: How the Entrepreneurial Spirit is Transforming the Public Sector. New York: Penguin Group.

Parry, K. W. (1996). Transformational Leadership: Developing an Enterprising Management Culture. Melbourne: Pitman/Woodslane Publishing.

Pressman, J.L. \& Wildavsky, A.B. (1973). Implementation: How Great Expectations in Washington are dashed in Oakland. Berkley: 
University of California Press.

Sepaela, P. (2013). Lt Gen Mbekela announces an ambitious plan. Journal, February/March. South African Police Service Corporate Communication.

Sepic, TF. (1996). Public Sector Change Strategy: A Current Look at Successes, Obstructions to Implementation and Burnout. Public Productivity and Management Review, 20(1).

Starling, G. (1998). Managing the Public Sector (5th Ed). Fort Worth: Harcourt Brace College Publishers.

South Africa, 1994. White Paper on Reconstruction and Development. Pretoria: Government Printer.

South Africa. 1996. The Constitution of the Republic of South Africa 108 of 1996. Pretoria: Government Printer.

South Africa. 1997. White Paper on Transforming Public Service Delivery: Batho Pele-"People First". Pretoria: Government Printer.

South Africa, 1999. Department of Public Service and Administration

Public Service Regulations, 1999. (Government Notice R679 of 1999). Government Gazette, 409(20117), 1 July $1999=$ Regulation Gazette no. 6544.

South Africa, 1999. Public Finance Management Act, 1999, Act No. 1 of 1999. Pretoria: Government Printer.

Stodgill, R.M. (1974). Handbook of Leadership: A Survey of Theory and Research. New York: The Free Press.

Tshikwatamba, N.E. (2003). Promoting collective management: Integration of African wisdom in the work place. Journal of Public Administration, 38(3): September. 
